\title{
POSISI KERJA DENGAN KELUHAN NYERI PUNGGUNG BAWAH PADA PENJAHIT PAKAIAN
}

\author{
Kamariah, Arifin, Gunung Setiadi \\ Poltekkes Kemenkes Banjarmasin Jurusan Kesehatan Lingkungan \\ Jl. H. Mistar Cokrokusumo No.1A Banjarbaru Kalimantan Selatan 70714 \\ E-mail: kamariah0012@gmail.com
}

\begin{abstract}
Work Position with Low Back Pain Complaints on Clothes Tailors. Low back pain is one of the musculoskeletal disorders resulting from the wrong ergonomics. Such conditions can occur in the informal work sector, such as clothes tailors at the Martapura Bauntung Batuah Market. The purpose of this study was to determine the relationship of work position with complaints of lower back pain in clothes tailors at the Bauntung Batuah Market Martapura. This study is an analytical study with a cross-sectional approach. The sampling technique uses total sampling with criteria for male sex so that the number of samples is 43 people. Data will be analyzed using the $x^{2}$ test (Chi-square). The results of the statistical analysis obtained the value of the work position p-value of 0,000 meaning that there is a relationship between the work position and complaints of lower back pain in the clothes tailor at the Martapura Bauntung Batuah Market. For other researchers, further research needs to being done on other factors such as individual factors and physical environmental factors that can cause complaints of lower back pain.
\end{abstract}

Keywords: Work position; Low back pain

Abstrak: Posisi Kerja Dengan Keluhan Nyeri Punggung Bawah Pada Penjahit Pakaian. Nyeri punggung bawah merupakan salah satu gangguan musculoskeletal akibat dari ergonomi yang salah. Kondisi tersebut dapat terjadi paada sektor kerja informal seperti penjahit pakaian di Pasar Bauntung Batuah Martapura. Tujuan penelitian ini untuk mengetahui hubungan posisi kerja dengan keluhan nyeri punggung bawah pada penjahit pakaian di Pasar Bauntung Batuah Martapura. Penelitian ini merupakan penelitian analitik dengan pendekatan cross sectional. Teknik pengambilan sampel menggunakan total sampling dengan kriteria sampel berjenis kelamin laki-laki sehingga jumlah sampel adalah 43 orang. Data akan dianalisis data menggunakan uji $x^{2}$ (Chi square). Hasil uji statistik diperoleh nilai $p$ value posisi kerja sebesar 0,000 artinya ada hubungan antara posisi kerja dengan keluhan nyeri punggung bawah pada penjahit pakaian di Pasar Bauntung Batuah Martapura. Bagi peneliti lain perlu dilakukan penelitian lebih lanjut mengenai fakto-faktor lain seperti faktor individu maupun faktor lingkungan fisik yang dapat menyebabkan keluhan nyeri punggung bawah.

Kata Kunci: Posisi kerja; Nyeri punggung bawah

\section{PENDAHULUAN}

Pertumbuhan penduduk yang relatif cepat akan mempersempit lowongan kerja sehingga pertumbuhan ekonomi semakin terhambat. Apalagi telah memasuki era globalisasi yang merupakan era perdagangan bebas pada semua bidang, menimbulkan persaingan antara tenaga kerja khususnya pada sektor formal. Kondisi ini pun mendorong sebagian dari golongan masyarakat membuka usaha kecil-kecilan di sektor informal untuk memperoleh penghasilan baik untuk dirinya sendiri maupun untuk keluarganya. Salah satu tempat untuk terciptanya sektor informal adalah pasar yang berfungsi tidak hanya sebagai tempat transaksi jual beli tetapi juga dijadikan tempat untuk membuka peluang usaha bagi masyarakat yang memiliki keterampilan tertentu dan modal yang minim. Salah satu diantaranya adalah usaha dibidang menjahit. Salah satu pasar yang menyediakan tempat untuk penjahit adalah pasar Bauntung Batuah Martapura[1]. 
Tersedianya kawasan perindustrian ini maka dituntut kemampuan sumber daya manusia yang berkualitas dan memiliki kondisi kesehatan yang prima untuk meningkatkan produktivitas kerja guna memperoleh keluaran yang maksimal, sehingga mampu bersaing dalam menghasilkan barang dan jasa yang bermutu tinggi. Namun umumnya usaha sektor informal belum memperhatikan dengan serius masalah yang berkenaan dengan ergonomi, mulai dari posisi kerja, peralatan kerja dan penyesuaian antara peralatan kerja dengan kondisi tenaga kerja yang menggunakan peralatan. Dengan kurangnya perhatian akan penyesuaian tempat kerja, posisi, serta peralatan terhadap tenaga kerja, tentunya akan menimbulkan beberapa permasalahan berupa penyakit akibat kerja ${ }^{[2]}$.

Berdasarkan Undang-undang Nomor 36 tahun 2009 tentang kesehatan, khususnya pasal 16 ayat 1 dan 2 tentang kesehatan kerja bahwa "Upaya kesehatan kerja ditunjukkan untuk melindungi pekerja agar hidup sehat dan terbebas dari gangguan kesehatan serta pengaruh yang diakibatkan oleh pekerja, baik pada pekerja sektor formal atau informal". Usaha sektor informal merupakan salah satu usaha yang memiliki risiko kesehatan yang cukup tinggi. Banyak penyakit akibat kerja yang timbul disektor ini, namun itu diabaikan saja oleh pemilik usaha atau pekerja itu sendiri. Salah satu usaha informal yang banyak terdapat di Indonesia dan memiliki risiko kesehatan yang cukup tinggi adalah usaha menjahit. Pekerjaan menjahit dilakukan dalam posisi kerja duduk yang cukup lama, kurang lebih 4-8 jam per hari dan dilakukan terus menerus. Posisi duduk yang salah dan duduk terlalu lama dan kursi yang tidak ergonomi menyebabkan timbulnya keluhan nyeri punggung bawah[3].

Nyeri Punggung Bawah (Low back pain) merupakan salah satu gangguan musculoskeletal akibat dari ergonomi yang salah. Gejala utama low back pain adalah rasa nyeri di daerah tulang belakang bagian punggung. Secara umum nyeri ini disebabkan karena peregangan otot dan bertambahnya usia yang akan menyebabkan intensitas olahraga dan gerak semakin berkurang. Hal ini akan menyebabkan otot-otot punggung dan perut akan menjadi lemah. Faktor risiko lain yang turut mempengaruhi timbulnya nyeri punggung bawah antara lain umur, jenis kelamin, indeks massa tubuh (IMT), masa kerja, dan kebiasaan olahraga ${ }^{[4]}$.

Penyebab low back pain yang paling sering adalah duduk terlalu lama, sikap duduk yang tidak tepat, postur tubuh yang tidak ideal (improper), aktivitas yang berlebihan, serta trauma. Nyeri punggung lalu menjadi masalah di banyak negara, karena seringkali mempengaruhi produktivitas kerja ${ }^{[5]}$.

Hasil observasi dan wawancara langsung pada tanggal 13 Oktober 2018 kepada 13 orang penjahit pakaian mengenai keluhan nyeri punggung bawah, rata-rata penjahit bekerja selama 5-8 jam perhari dengan posisi kerja duduk membungkuk kedepan dan kepala menunduk. Dari 13 orang penjahit tersebut ada 9 orang penjahit yang mengeluh pernah mengalami nyeri punggung bawah saat bekerja mengoperasikan mesin jahit, 1 orang penjahit mengeluh hanya pegalpegal dibagian punggung bawah dan 3 orang penjahit tidak pernah mengalami nyeri punggung bawah.

\section{BAHAN DAN CARA PENELITIAN}

Jenis penelitian ini bersifat analitik rancangan cross sectional yang bertujuan mengetahui hubungan posisi dengan keluhan nyeri punggung bawah pada penjaht pakaian di Pasar Bauntung Batuah Martapura. Instrument yang digunakan dalam penelitian ini adalah kuesioner Modifed Oswestry LBP Disability yaitu kuesioner baku/standar yang digunakan untuk menilai tingkat keluhan nyeri punggung bawah pada tenaga kerja yang telah teruji validitas dan reabilitasnya dan peengamatan posisi kerja menggunakan lembar observasi dengan metode Rapid Entry Body Assesment (REBA) yaitu lembar observasi untuk mendapatkan gambaran resiko posisi kerja penjahit pakaian.

Populasi dalam penelitian ini adalah seluruh penjahit pakaian di Pasar Bauntung Batuah Martapura yang berjumlah 56 
orang. Teknik pengambilan sampel dalam penelitian ini menggunakan teknik total sampling dengan kriteria sampel berjenis kelamin laki-laki sehingga sampel menjadi 43 orang. Analisis data menggunakan statistik Chi-Square menggunakan program aplikasi di komputer.
HASIL PENELITIAN DAN PEMBAHASAN

Penelitian ini dilaksanakan di pasar Bauntung Batuah Martapura Kabupaten Banjar. Pasar ini menyediakan ruangan yang dikhususkan untuk penjahit tanpa bercampur dengan jenis pekerjaan lain, yaitu di Blok A lantai II. Hasil penelitian dapat dilihat pada tabel-tabel berikut ini:

Tabel 1. Distribusi umur penjahit pakaian

\begin{tabular}{cccc}
\hline No. & Umur & Jumlah (orang) & $\%$ \\
\hline 1. & Tua $(\geq 30$ Tahun $)$ & 37 & 86,05 \\
2. & Muda (<30 Tahun) & 6 & 13,95 \\
& Total & 43 & 100 \\
\hline
\end{tabular}

Tabel 1 menunjukkan bahwa dari 43 responden yang terbanyak adalah responden dengan kelompok umur tua ( $\geq 30$ tahun) yaitu sebanyak 37 orang $(86,05 \%)$.

Tabel 2. Distribusi masa kerja penjahit pakaian

\begin{tabular}{cccc}
\hline No. & Masa Kerja & Jumlah (orang) & $\%$ \\
\hline 1. & Lama $(\geq 3$ Tahun) & 40 & 93,02 \\
2. & Baru (<3 Tahun) & 3 & 6,98 \\
& Total & 43 & 100 \\
\hline
\end{tabular}

Tabel 2 menunjukkan bahwa dari 43 responden yang terbanyak adalah responden dengan kelompok masa kerja lama ( $\geq 3$ tahun) yaitu sebanyak 40 orang $(93,02 \%)$.

Tabel 3. Distribusi indeks massa tubuh penjahit pakaian

\begin{tabular}{cccc}
\hline No. & Masa Kerja & Jumlah (orang) & $\%$ \\
\hline 1. & BB Berlebih $(23-29,9)$ & 24 & 55,81 \\
2. & BB Ideal $(18,5-22,9)$ & 18 & 41,86 \\
3. & BB Kurang $(\leq 18,4)$ & 1 & 2,33 \\
& Total & 43 & 100 \\
\hline
\end{tabular}

Tabel 3 menunjukkan bahwa dari 43 responden yang terbanyak adalah responden dengan IMT berat badan berlebih $(23-29,9)$ yaitu sebanyak 24 orang $(55,81 \%)$.

Tabel 4. Distribusi posisi kerja penjahit pakaian

\begin{tabular}{cccc}
\hline No. & Posisi Kerja & Jumlah (orang) & $\%$ \\
\hline 1. & Risiko Sedang & 25 & 58,14 \\
2. & Risiko Sedang & 18 & 41,86 \\
& Total & 43 & 100 \\
\hline
\end{tabular}

Tabel 4 menunjukkan bahwa dari 43 responden yang terbanyak adalah responden dengan risiko posisi kerja sedang yaitu sebanyak 25 orang $(58,14 \%)$.

Tabel 5. Distribusi keluhan nyeri punggung bawah penjahit pakaian

\begin{tabular}{cccc}
\hline No. & Keluhan NPB & Jumlah (orang) & $\%$ \\
\hline 1. & Ada Keluhan & 24 & 55,81 \\
2. & Tidak Ada Keluhan & 19 & 44,19 \\
& Total & 43 & 100 \\
\hline
\end{tabular}


Tabel 5 menunjukkan bahwa dari 43 responden yang terbanyak adalah responden dengan keluhan nyeri punggung bawah yaitu sebanyak 24 orang $(55,81 \%)$.

Tabel 6. Hubungan posisi kerja dengan keluhan nyeri punggung bawah

\begin{tabular}{cccccccc}
\hline Posisi Kerja & \multicolumn{3}{c}{ Keluhan Nyeri Punggung Bawah } & \multicolumn{2}{c}{ Jumlah } & \multirow{2}{*}{ P-value } \\
& \multicolumn{2}{c}{ Ada Keluhan } & \multicolumn{2}{c}{ Tidak Ada Keluhan } & F & $\%$ & 0,000 \\
Risiko Sedang & $\mathrm{F}$ & $\%$ & $\mathrm{~F}$ & $\%$ & $\mathrm{~F}$ & $\%$ & \\
Risiko Rendah & 22 & 88 & 3 & 6,98 & 12 & 100 & \\
& 2 & 11,11 & 16 & 88,89 & 18 & 100 & \\
& & & & & 43 & 100 & \\
\hline
\end{tabular}

Tabel 6 menunjukkan bahwa secara statistik terdapat hubungan antara posisi kerja dengan keluhan nyeri punggung bawah karena nilai $p$-value sebesar $0,000<$ alpha $(0,05)$.

Berdasarkan hasil observasi ratarata kursi yang dipakai oleh penjahit mempunyai sandaran punggung. Namun, seringkali tidak memanfaatkan sandaran punggung tersebut dalam bekerja dikarenakan penjahit ingin mencapai target penglihatan visual mata dalam hal ini pada saat melakukan proses penjahitan dan ada juga beberapa penjahit yang tidak mempunyai sandaran sehingga cenderung duduk dengan posisi membungkuk. Hal inilah yang menyebabkan timbulnya keluhan nyeri punggung bawah. Kebanyakan kursi yang digunakan penjahit berbahan dasar kayu yang didesain tanpa disesuaikan dengan ukuran tubuh serta tidak dapat diatur ketinggiannya. Banyaknya penjahit yang menggunakan kursi kerja tidak sesuai dapat berakibat buruk bagi kesehatan. Ketidaksesuaian tinggi kursi kerja menyebabkan tubuh penjahit berusaha untuk menyesuaikan dengan kursi yang digunakan. Oleh karena itu, posisi penjahit pada waktu bekerja menjadi tidak ergonomis, seperti posisi duduk dengan kaki menggantung yang mengakibatkan paha tidak dalam keadaan datar, sehingga penjahit akan memajukan posisi duduknya agar dapat melakukan pekerjaannya. Selain itu, sikap penjahit yang membentuk posisi tubuh menunduk ataupun membungkuk ketika bekerja akibat penggunaan kursi yang terlalu tinggi. Keadaan tersebut menimbulkan keluhan nyeri punggung bawah yang berkaitan dengan posisi duduk pada waktu bekerja.

\section{KESIMPULAN DAN SARAN}

Penjahit dengan posisi kerja risiko rendah sebanyak 18 orang $(41,86 \%)$ dan posisi kerja risiko sedang sebanyak 25 orang $(58,14 \%)$. Penjahit dengan posisi kerja risiko sedang yang mengeluh nyeri punggung bawah sebanyak 22 orang $(51,16 \%)$ dan yang tidak mengeluh sebanyak 3 orang $(6,98 \%)$. Penjahit dengan posisi kerja risiko rendah yang mengeluh nyeri punggung bawah sebanyak 2 orang $(4,65 \%)$ dan yang tidak mengeluh sebanyak 16 orang $(37,21 \%)$. Ada hubungan antara posisi kerja dengan keluhan nyeri punggung bawah. Bagi peneliti lain perlu dilakukan penelitian lebih lanjut mengenai fakto-faktor lain seperti faktor individu maupun faktor lingkungan fisik yang dapat menyebabkan keluhan nyeri punggung bawah.

\section{KEPUSTAKAAN}

1. Laila N. Hubungan Intensitas Penerangan dengan Keluhan Subjektif Pada Ruang Kerja Penjahit Pakaian di Pasar Niaga Blok A Lantai II Martapura. Banjarmasin: Politeknik Kesehatan Kementerian Kesehatan Banjarmasin; 2010.

2. Notoatmodjo S. Pendidikan dan Perilaku Kesehatan. Jakarta: Rineka Cipta; 2003.

3. Ahmad A, Budiman F. Hubungan Posisi Duduk Dengan Nyeri Punggung Bawah Pada Penjahit Vermak Levis Di Pasar Ttanah Pasir Kelurahan Penjaringan Jakarta Utara Tahun 2014. 2014;412-20. 
4. Umami AR, Hartanti RI, S ADP. Hubungan antara Karakteristik Responden dan Sikap Kerja Duduk dengan Keluhan Nyeri Punggung Bawah ( Low Back Pain ) Pada Pekerja Batik Tulis ( The Relationship Among Respondent Characteristic and Awkward Posture with Low Back Pain in Batik Workers ). 2014;2(1):72-8.

5. Rachmawati LD. Hubungan Sikap Kerja Duduk Dengan Keluhan Nyeri Punggung Bawah Pada Pekerja Rental Komputer di Pabelan Kartasura. Surakarta: Universitas Muhammadiyah Surakarta; 2008. 
